\title{
Pias Voluntades
}

\section{For Monseñor LUIS LITUMA PORTOCARRERO}

\section{Catedrático titular de Derecho Canónico}

"La voluntad es la potencia dominadora en el hombre, es la reina de todas las otras facultades y potencias, la que las gobiema; es ella quien, por ser libre, comunica a sus actos, no solamente a los propios suyos, los elícitos, sino también a los que realizan las otras potencias bajo su imperio, a los imperados, la libertad, el mérito y el demérito. Ordenada bien la voluntad queda ordenado el hombre entero". (Tanquerey: Comp. de Thl. asc. y mist. n. 811).

El valor de la humana voluntad trasciende el orden ético-individual, informa la vida social humana, desarróllese ésta en sociedades necesarias - libres, en sociedades norturales o sobrenaturales.

La voluntad es jurisgenética, engendra derechos y obligaciones en todo acto jurídico $\mathrm{y}$ hace que los "contratos alcancen de la convención fuerza de ley". (Rgl. CLXXXV, in VI\%).

La virtud de la piedad nos inclina a rendir a Dios veneración, culto y amor filiales y a tratar a nuestros prójimos como hermanos, hijos del Padre Celestial que hace salir el sol para los buenos y para los malos. Si la piedad mueve nuestra voluntad las voliciones nuestras serón "pías voluntades", "piadosas voliciones", las cuales normalmente se traducirán en actos externos y de proyecciones sociales. Aunque merecen el nombre de "piadosas voliciones o pías voluntades" todos los actos libres que son engendrados por la devoción, como un voto, una peregrinación, etc., sin embargo, el "uso" que es, en frase de Horacio, "ley y norma de hablar", el uso, digo, especialmente el de los moralistas y canonistas, reserva el nom. bre de "pías voluntades a las disposiciones de bienes patrimoniales que hace un cristiano para que ellos se opliquen al culto divino, al bien de las almas o a la práctica de las obras de misericordia que nos preceptuó nuestro divino Salvador".

Esta disposición de los propios bienes debe hacerse por un fin sobrenatural - sea de religión o de caridad-, para que pueda llamarse "pía voluntad".

Sinónimo de "pía voluntad" es "causa pía": la primera locución con 
nota la causa eficiente, la segunda la final, pues en el lenguaje juríảico "ccusa" significa "negocio contraído o celebrado, "lid", "condición", "la razón de un acto" y "Ia finalidad", o sea "lo que se persigue con el acto", "aquello por lo cual se hace algo", sentido, éste último que se aplica a nuestro caso.

Las "pías voluntades" o "causas pías" en razón de su destinación esencial que las distingue de todo otro querer jurídico y de toda otra causa, estón dentro de la esfera jurisdiccional de la Iglesia, pues "todo cuanto en este mundo tiene de algún modo algo de sagrodo, todo lo que se refiere a la scivación de las almas y al culto divino, sea por su misma naturaleza, sea por su destinación, cae bajo el dominio de la Iglesia". (León XIII: Enc. Immortale Dei). La Iglesia, pues, tiene derecho propio y nativo, independiente de la autoridad civil a legislar, juzgar, administrar las pías vo. Iuntades de los fieles.

De aquí que puedan disponer de sus bienes en favor de las causas pías todos aquellos que por derecho natural, por derecho divino y por derecho eclesiástico tienen libre disposición de sus bienes. Así, por ejemplo, ni el loco, ni el infante, ni el que carece de bienes o los tiene obligados ya hacia un tercero - por una deuda, por obligación de alimentar a sus descendientes-, podrían disponer de sus bienes para causas pías; no los primeros porque son incapaces absolutamente de todo acto jurídico, no el último porque "primero es la obligación que la devcción" y no sería verdadera la de quien donara el dinero que debe a sus acreedores quedóndose en voluntaria insolvencia para pagarlos, ni de quien dejara de alimentar y educar a sus hijos por hacer un acto que no le es preciso realizar. El derecho natural haría nulas tales disposiciones ad causas pías. Este mismo derecho anularía una pía voluntad del superior de un Convento que procedierc, motu proprio, a disponer de los bienes de la masa común, pues él no es el dueño.

Según nuestro Código Civil, los acios jurídicos de los absolutamente incapaces son nulos ipso iure (art. 1123, 19,1075) y de acción declarativa de la nulidad de ese acto; y considera irritables los de los relativamente incapaces, irrilabilidad que puede pedir usando acción recisoria, aquel en cuyo favor se ha establecido la incapacidad (art. 1125, $1^{\circ}$ y l126).

Como el Código Piano-Benedictino considera únicamente como razones capaces de irritar una dispozición ad causas pías, las que dimanan del derecho divino y del eclesiústico, dedúcese que en tanto valen las disposiciones de nuestro Código Civil en el asunto que nos ocupa en cuanto coinciden con las disposiciones canónicas.

Como los que adolecen de enfermedad mental que los priva de discernimiento, los sordo-mudos que no saben expresar su voluntad de una manera indubitable son incapaces, por derecho natural, de hacer cualquier acto jurídico támbién lo son por derecho eclesiástico.

El canon 89 sienta el principio general que los "menores de veintiún años están sujetos a la potestad de sus padres en el ejercicio de sus derechos, sclvo en el de aquellos en los cuales el derecho los considera exenios de la patria potestad". In forma explícita hablan de esta excepción los 
cánones 1934, 1640, 93, pero nada dicen formalmente sobre la disposición de los bienes que hagan los menores que gozan ya del uso de la razón. Cabe, pues, dos interpretaciones:

a) la de considerarlos incapaces de hacer tal disposición ad causas pías. El argumento podría ponerse en esta forma: "los menores no pueden ejercer sus derechos si no es sujetándose a la potestad paterna, salvo los casos exceptuados; no se ha exceptuado la disposición de bienes ad causas pías, luego......"

b) la de considerarlos capaces. Según la parte primera del canon 1513: "Quien puede disponer libremente, por derecho natural o eclesióstico de sus bienes, puede dejar sus bienes a las causas pías, sea por acto inter vivos o por acto mortis cciusa"; es así que ni el derecho natural, ni el eclesióstico obstan a que el menor deje sus bienes para las causas pías; luego.....

Además, el menor puede, lícita y válidamente, escoger $\mathrm{y}$ abrazar un estado de vida que lleva obligaciones perpetuas y gravísimas, tales como el sacerdotal, el religioso o el conyugal, aun contra la voluntad de sus padres; luego a fortiori podró privarse de algunos bienes patrimoniales por un motivo sobrenctural.

Más aún, según el canon 1648, los menores que han llegado al uso de razón pueden ser actores y responder en juicio, sin el consentimiento del padre o del tutor, siempre que se trate de cosas espirituales o conexas con ellas; la razón de esta disposición radica en la autonomía que requiere el hombre en todo cuanto atañe $\alpha$ su fin sobrenatural, cualquiera que sea su edad; esta misma razón vale para defender la libertad de disponer ad causas pías en el menor.

Salvo mejor parecer, creemos que los menores que gozan de uso de razón y proceden a sabiendas y libremente, o sea, sin que en su determinación haya habido, ni dolo, ni fuerza, ni error substancial, ni miedo injusto, pueden disponer libremente de sus bienes ad causas pías y que esta voluntad engendra un verdadero derecho a favor de ellas. Como es evidente, si el menor diese dinero ajeno - de sus padres o de un tercero- o procediese de fuerza física o moral irresistibles o de error substancial la donación que hiciere de sus bienes, o parte de ellos, tal donación sería nula ipso iure (cn. 103-104). Si el menor procedió por error nacido del empleo de dolo, tendría acción rescisoria para pedir la anulación de su donación (cn. 103, 104, 1684-1689). Como toda donación no es perfecta hasta que no haya sido aceptada, los rectores de las iglesias, beneficiados y superiores de las casas religiosas si prudentemente previeran que la aceptación de tales donaciones habrían de producir una reacción hostil a la Iglesia o en daño del prestigio del clero deben consulțar al Ordinario exponiendo las circunstancias del caso para poder renunciarlas, ya que no lo podrían hacer motu proprio. (Cn. 1636, prr. 2). Empleando esta medida de elemental prudencia se evitará la dificultad que fácilmente ocurre contra nuestra tesis, que de admitir las donaciones de los menores sin consentimiento del padre o tutor nacerían innumerables dificultades y litigios.

Lo dicho acerca de las donaciones de los menores de edad puede aplicarse $\alpha$ las que hicieren personas consideradas por nuestro Código Civil 
como relativamente incapaces, a saber: los sujetos a curatela por ser pródigos declarados, haber incurrido en mala gestión, sufrir interdicción civil (art. 10 y 125, 1126).

Como es obvio, mayor cautela aún se requiere para aceptar la donación ad causas pías de un débil mental, por nuestro C. C., considerado entre los relativamente incapaces, pues cabe que el débil mental sea incapaz de acto plenamente libre, máxime en la disposición de sus bienes.

Por el canon 1513 (que ya hemos trascrito), se rigen las donaciones piadosas, no sólo en lo que atañe a la capacidad de las personas, sino también a la cantidad de lo que puede ser donado-que nuestro Código limita en función de lo que cada cual puede disponer libremente sin violar la legítima-, y a las solemnidades de las donaciones, pues las donaciones ad causas pías están sujetas únicamente al derecho canónico y al derecho natural, mas no al derecho civil; por lo tanto: "si tales donaciones por la ley civil fueren tenidas (o absolutamente o bajo ciertas condiciones), por íritas, serían, sin embargo, válidas en el fuero de la conciencia, y esto aunque una sentencia judicial las declarase nulas o las anulase, siempre que en ellas se hubiesen observado las prescripciones de derecho natural para la validez de las mismas". (Noldin-Schmitt (1941): Thl. Mor. II, 550).

Por derecho natural la validez de la donación sólo exige: que el donante libremente done lo suyo; que el donatario o su representante legítimo acepte la donación.

Como la donación requiere máxima libertad, si fuese hecha por miedo, aunque éste fuese leve, podría pedirse la rescisión. (Marc.: T. M. N $\mathbf{N}^{\mathbf{O}}$ 1050; Aertnys-Damen: T. M. I, 853, iii, 2).

La doctrina que acabormos de proponer acerca de las donaciones inter vivos debe ser aplicada a las mortis causa, y a aquellas que se hicieren por testamento, sea transfiriendo toda la herencia, sea dejando uno o más legados. El párrafo 2 del canon 1513 es terminante:

"En las últimas voluntades a favor de la Iglesia obsérvense, si fuere posible, las solemnidades de derecho civil; si éstas fueren omitidas amonéstese a los herederos que cumplon la voluntad del testador". Tal amonestación no es de consejo, es un precepto según lo declaró la C. I. del C. el 17 de febrero de 1930 .

Saquemos ahora algunas consecuencias prócticas:

$l^{\alpha}$ Quien libremente donó sus bienes a una cousa pía no puede reivindicarlos, pues la "reivindicatio" presupone que lo que se pide es nuestro, y en el caso ya no es del donante sino de la Iglesia;

$2^{\alpha}$ Los herederos no pueden pedir la nulidad de tales donaciones, alegando que en ellas se excedió la cantidad de libre disposición, o que no se observó la solemnidad requerida por la ley civil;

$3^{a}$ Ningún abogado puede cooperar en defender semejante petición, pues si éste viola la justicia es ilícita y defender la injusticia es también ilícito: 
$4^{\alpha}$ Unicamente como un medio de evifar mayores daños podría aconsejar una transacción, la cual, como envuelve para la persona jurídica eclesióstica que la ha recibido una verdadera alienación, ésta no padría proceder válidamente si no alcanza previamente la licencia, sea del Ordinario, sea de la Santa Sede o de quien tuviere facultad delegada para darla, según sea el monto a que habría de renunciar. 